ISSN: 2091-0657 (Print); 2091-0673 (Online)

Open Access

\title{
Knowledge, Attitude and Practice of nursing students on Hospital Acquired Infections in Western region of Nepal
}

\author{
Ishwari Sharma Paudel ${ }^{1}$, Vivek Ghosh ${ }^{2}$, Purushottam Adhikari ${ }^{2}$ \\ School of Public Health and Community Medicine, B.P. Koirala Institute of Health Sciences, Dharan \\ Gandaki Medical College Teaching Hospital, Pokhara
}

\section{Correspondence}

Dr. Ishwari Sharma Paudel

School of Public Health and

Community Medicine, B.P.

Koirala Institute of Health

Sciences, Dharan

Email: is_paudel@yahoo.com

DOI: http://

dx.doi.org/10.3126/

jcmsn.v12i3.16012

Article received: $\operatorname{Aug} 5^{\text {th }}$

2016

Article accepted: Sept $2^{\text {nd }}$

2016

\begin{abstract}
Background \& Objectives: Hospital-acquired infections (HAIs) are a common problem and challenge faced by hospitals in all countries around the world. Nurses are an important part of the healthcare team that plays a unique role in the control of HAIs. Compliance on the part of healthcare workers (HCWs) including nurses with standard precautions has been recognized as being an efficient means to prevent and control HAIs. The present study was conducted with objective of understanding the level of Knowledge, attitude and practice (KAP) regarding HAIs among nursing students in the Western Region of Nepal. Materials \& Methods: This descriptive cross-sectional study was conducted among nursing students posted in different wards of two hospitals of Pokhara. A self administered questionnaire containing different set of questions regarding knowledge, attitude and practice on HAI were used for data collection. Results: Among the total participants in the study $97 \%$ of the participants considered that prevention of HAIs were a valuable part of nurses' role but only $89 \%$ had received formal training regarding hand hygiene. The results show that $74 \%$ of the participants had good knowledge regarding HAIs. $82 \%$ of the participants felt that they would be less likely to transmit infection to the patient if they performed handhygiene. $66 \%$ of them identified that hand hygiene agents were not readily available in current settings. Regarding practice, only $6 \%$ performed hand hygiene before patient contact. Conclusion: The nursing students had good knowledge regarding HAIs that was reflected in their attitude and practice on hand hygiene for the prevention of HAIs. However there is the need of regular training and performance feedback regarding hand hygiene and the hospital environment should be handhygiene friendly with easily accessible to sinks and other facilities.
\end{abstract}

Key words: HAIs; HCWs; KAP; Hand-hygiene; Hand-washing.

Citation: Paudel IS, Ghosh V, Adhikari P. Knowledge, Attitude and Practice of nursing students on Hospital Acquired Infections in Western region of Nepal. JCMS Nepal. 2016;12(3):103-7.

\section{INTRODUCTION}

Nosocomial infections are infections acquired in the hospital or other health care facilities that were not present or incubating at the time of the client's admission. It is also referred to as hospital-acquired infections (HAIs). It includes those infections that become symptomatic after the client is discharged as well as infections among medical personnel. Most nosocomial infections are transmitted by health care personnel who fail to practice proper hand washing procedures or change gloves between client contacts. ${ }^{1}$
A prevalence survey conducted under the auspices of WHO in 55 hospitals of 14 countries representing 4 WHO Regions (Europe, Eastern Mediterranean, South-East Asia and Western Pacific) showed an average of $8.7 \%$ of hospital patients had nosocomial infections. At any time, over 1.4 million people worldwide suffer from infectious complications acquired in hospital. The highest frequencies of nosocomial infections were reported from hospitals in the Eastern Mediterranean and South-East Asia Regions ( 11.8 and $10.0 \%$ respectively). ${ }^{2}$

Identifying existing infection control knowledge, 
attitudes, and practices (KAP) among health care workers (HCWs) is a key first step in developing a successful infection control program. In an effort to raise awareness and provide guidance in combating HAIs in resource limited settings (RLS), the World Health Organization (WHO) launched the Global Patient Safety Challenge: Clean Care is Safer Care campaign. ${ }^{3}$ A cornerstone of the program is to decrease HAIs through improving hand hygiene among healthcare workers. While the WHO campaign has outlined a framework, hand hygiene adherence continues to be problematic even though it is a simple and highly effective measure to reduce HAIs. ${ }^{4,5}$

Among the standard precautions advocated, hand hygiene is considered, in itself, the most important one. Another important measure is the adequate use of gloves, whose purpose is to protect the HCWs, as well as the patient. ${ }^{6}$ While adherence with hand hygiene is poor in both developed and developing nations, barriers to implementation of a successful hand hygiene program may be different in resource limited settings. ${ }^{7}$ Poor compliance is associated with lack of awareness among personnel. ${ }^{8}$ The other factors are personnal and organizational attitude towards interventions like hand washing, cost containment and logistical barriers. ${ }^{9}$

The education regarding HAIs has a positive impact on retention of KAP in all categories of health workers to prevent infections. ${ }^{10}$

The purpose of our study was to understand the level of KAP among the nursing students regarding HAIs in the Western Region of Nepal. It also aims to identify the barriers in adopting proper infection prevention measures by HCWs and suggest hospital authorities for betterment of necessary facilities to adopt more pragmatic approach in helping to reduce such infections.

\section{MATERIALS AND METHODS}

Study design: Descriptive-cross-sectional study conducted among the nursing students in the Western region of Nepal.

Study site: Gandaki Medical College Teaching Hospital (GMCTH) and Fewacity Hospital (FCH), Pokhara

Study population: PCL Nursing students posted at different in-patient wards of the hospitals

Sample size: 117

Study period: May-June, 2016

Sampling procedure: All nursing students available at different wards of the hospitals during the survey were included in the study.
Instruments and Techniques: Semi structured, pre tested self administered questionnaire consisting of questions on knowledge, attitude and practices on HAIs.

Knowledge was assessed using 10 questions with options either "yes" or "no". Attitude and practice were assessed using another set of questionnaire consisting 14 and 8 questions respectively. The respondents were given "yes" or "no" options to select based on their attitude and practice regarding HAIs.

All the questions were subjected to a pre-testing prior to the study and obtained suggestions were taken into consideration.

A scoring system was used where 1 point was awarded for each correct response to knowledge, positive atti-tudes, and good practices. Incorrect knowledge, negative attitudes, and poor practices were given 0 points. The cut-off values to determine good, moderate, and poor levels were taken from previously published studies with some modification to suit our purpose. A score greater than $75 \%$ was considered good, $50 \%-74 \%$ moderate and less than $50 \%$ poor.

Data Analysis: Data was analyzed using Microsoft excel 2010 software.

Ethical considerations: Ethical clearance was obtained from the Institutional Ethical Committee of Gandaki Medical College.

\section{RESULTS}

Knowledge on Hospital acquired infections:

$74 \%$ (86 out of 117) of the correspondents had good knowledge regarding HAIs. However, 26\% still lacked good knowledge regarding HAIs. Highest proportion of the correspondents( 94\%) were aware of the fact that washing hands with soap or an alcohol based antiseptic decreases the risk of transmission of hospital acquired pathogens. Similarly, $94 \%$ of them disagreed to the fact that hand washing is not necessary if the hand are not visibly dirty and that there is need to wash hands before doing procedures that involve bodily fluids. A larger proportion $(74 \%)$ of the correspondents still considered that gloves provided complete protection against acquiring/ transmitting infections. Only $88 \%$ of them realized that same pair of gloves cannot be worn for multiple patients as long as there is no visible contamination on the gloves and it should be changed after each patient contact. The percentage of participants who considered that healthcare-associated pathogens can 
Table 1: Knowledge on Hospital acquired infections (Correct responses):

\begin{tabular}{|c|c|c|c|}
\hline & Questions & $\mathrm{N}=117$ & $\%$ \\
\hline K1 & $\begin{array}{l}\text { Gloves provide complete protection against acquiring/transmitting infection } \\
\text { (false) }\end{array}$ & 31 & 26 \\
\hline K2 & $\begin{array}{l}\text { Healthcare-associated pathogens can be found on normal, intact patient skin } \\
\text { (true) }\end{array}$ & 91 & 78 \\
\hline K3 & $\begin{array}{l}\text { Washing your hands with soap or an alcohol based antiseptic decreases the } \\
\text { risk of transmission of hospital acquired pathogens (true) }\end{array}$ & 110 & 94 \\
\hline K4 & $\begin{array}{l}\text { If my hands are not visibly dirty, there is no need to wash my hands prior to } \\
\text { patient contact (false) }\end{array}$ & 110 & 94 \\
\hline K5 & $\begin{array}{l}\text { Use of an alcohol based antiseptic for hand hygiene is as effective as soap and } \\
\text { water if hands are not visibly dirty (true) }\end{array}$ & 71 & 61 \\
\hline K6 & Gloves should be worn if blood or body fluid exposure is anticipated (true) & 102 & 87 \\
\hline K7 & $\begin{array}{l}\text { When using alcohol based antiseptics, I should keep rubbing my hands until } \\
\text { dry (true) }\end{array}$ & 82 & 70 \\
\hline K8 & $\begin{array}{l}\text { There is no need to wash hands before doing procedures that do not involve } \\
\text { bodily fluids (false) }\end{array}$ & 110 & 94 \\
\hline K9 & $\begin{array}{l}\text { Hand hygiene should be performed before and after direct patient contact } \\
\text { (true) }\end{array}$ & 113 & 97 \\
\hline K10 & $\begin{array}{l}\text { I can wear the same pair of gloves for multiple patients as long as there is no } \\
\text { visible contamination on the gloves (false) }\end{array}$ & 103 & 88 \\
\hline
\end{tabular}

be found on normal, intact patient skin was $91 \%$ whereas the rest $(6 \%)$ believed that intact skin does not harbor pathogens. The knowledge that when using alcohol based antiseptics, hands should be rubbed until dry prevailed among $70 \%$ of the participants. The fact that hand hygiene act should be performed before and after direct patient contact was agreed upon by $97 \%$ of the study population.

\section{Attitude on Hospital acquired infections:}

In relation to attitude of the nursing students majority of the nursing students $(82 \%, 96$ out of 117) felt that they would be less likely to transmit infection to the patient if they performed handhygiene. $89 \%$ (105 out of 117) of the nursing students had received formal training regarding hand hygiene but the rest $(11 \%)$ had received no formal training and 85\%(100 out of 117) thought their supervisors stressed on the importance of hand hygiene. Regarding various hindrances in adoption of hand hygiene, most of the correspondents $(66 \%$, 77 out of 117) identified that hand hygiene agents (alcohol based hand sanitizer or soap \& water) were not readily available, $68 \%$ (79 out of 117 ) identified that clean towels to dry their hands after washing are not always available, $50 \%$ identified that the sinks were inconveniently located, and $28 \%$ felt that hand hygiene agents cause irritation and dryness. Notably $47 \%$ identified hand hygiene as interference in HCW-patent interactions. 97\% (113 out of 117) participants considered that prevention of HAIs is a valuable part of nurse's role. $26 \%$ of the nursing students reported that they often forgot to perform hand hygiene.

\section{Practice on hospital acquired infections:}

With respect to hand hygiene practices, only $6 \%$ performed hand hygiene before patient contact. All of them (100\%) performed hand hygiene act after patient contact. If the hands felt or looked dirty, $84 \%$ of the participants performed hand hygiene. $98 \%$ of the correspondence performend hand hygiene after going to toilet, however still two percent didn't adhere to proper hand hygiene after going to toilet. $99 \%$ of the participants performed hand hygiene before caring for wound and all of them $(100 \%)$ after caring for the wound. Practice of hand hygiene after removal of gloves was performed by $96 \%$ of the participants.

\section{DISCUSSION}

In this part of the world there are very few studies conducted on HAIs and measures to prevent them. Knowledge of HAIs and compliance to the preventive methods such as proper practice of aseptic precautions lead to reduction in HAIs in the hospital settings.

In order to reduce HAIs in any hospital, knowledge of HAI and compliance to methods in preventing 
Table 2: Attitude on Hospital acquired infections (Responses on agreement):

$\begin{array}{llll} & \text { Questions } & \mathrm{N}=117 & \% \\ \text { A1 } & \text { Hand Hygiene agents are not always available. } & 77 & 66 \\ \text { A2 } & \text { Clean towels to dry my hands after washing are not always available. } & 79 & 68 \\ \text { A3 } & \text { Gloves are always available when needed. } & 61 & 52 \\ \text { A4 } & \text { Sinks are inconveniently located. } & 58 & 50 \\ \text { A5 } & \text { Sinks are not available } & 42 & 36 \\ \text { A6 } & \text { Hand hygiene agents cause irritation and dryness. } & 33 & 28 \\ \text { A7 } & \text { Hand hygiene interferes with HCW-patient interactions } & 55 & 47 \\ \text { A8 } & \text { I often forget to perform hand hygiene. } & 31 & 26 \\ \text { A9 } & \text { I have a very low risk of acquiring infections from my patients. } & 42 & 36 \\ \text { A10 } & \text { If I perform hand hygiene, I am less likely to transmit infections to my } & 96 & 82 \\ \text { A11 } & \text { patients. Prevention of HAIs is a valuable part of HCWs role. } & 113 & 97 \\ \text { A12 } & \text { I have received training about the importance of hand hygiene } & 105 & 90 \\ \text { A13 } & \text { The importance of hand hygiene is emphasized by my clinical supervisors. } & 100 & 85 \\ \text { A14 } & \text { I would feel uncomfortable reminding a HCW to perform hand hygiene. } & 56 & 48\end{array}$

Table 3: Practice on Hospital acquired infections (Always/often responses):

\begin{tabular}{|c|c|c|c|}
\hline & Questions & $=117$ & $\%$ \\
\hline P1 & Before Patient Contact & 7 & 6 \\
\hline $\mathrm{P} 2$ & After Patient Contact & 117 & 100 \\
\hline P3 & If they look or feel dirty & 98 & 84 \\
\hline P4 & After going to the toilet & 115 & 98 \\
\hline P5 & $\begin{array}{l}\text { After contact with blood } \\
\text { or bodily fluids }\end{array}$ & 117 & 100 \\
\hline P6 & $\begin{array}{l}\text { Before caring for a } \\
\text { wound }\end{array}$ & 116 & 99 \\
\hline P7 & After caring for a wound & 117 & 100 \\
\hline P8 & After removing gloves & 112 & 96 \\
\hline
\end{tabular}

them like proper practice of aseptic and antiseptic precautions are very much essential.

In our KAP survey that was conducted among the students of two nursing institutions, we found good understanding of HAI and measures to prevent it. The knowledge regarding HAIs was good among majority of the participants. This is consistent with the study conducted among the $\mathrm{HCW}$ in Ethiopia in similar settings. ${ }^{11}$

Our study revealed that still $11 \%$ have not received any formal training in hand hygiene. A study conducted in India regarding the knowledge, attitude and practice of different group of HCW about infection control concluded that training has a positive impact on the improvement of KAP in health care personnel. They also suggested that development of continuous training program for all HCW is necessary. ${ }^{10}$

Potential barriers to implementation of effective prevention of HAIs via proper hand hygiene measures include lack of infrastructure, formal training, infection control role models and unavailability of hand hygiene products as well as hand hygiene products that cause skin irritation and dryness to a significant proportion of HCWs. Majority of the participants reported that hand hygiene agents like- alcohol based hand sanitizer, soap and water are not easily available. Similarly, clean towels to dry the hands after washing are also not always available. The sinks for washing purposes are inconveniently located and inadequate at the hospital-settings. This finding is in accordance to a similar study conducted in Sri Lanka in which dissatisfaction with facilities available for hand hygiene was high among the study group and likely to omit the hand hygiene practices when facilities are not easily accessible to them. Thus increasing the supplies necessary for hand washing and institutional support is essential in combating the substandard practices in hand hygiene. ${ }^{12}$ Limited accessibility of hand hygiene facilities has been shown to be an important risk factor for poor adherence to recommendations. ${ }^{13}$

Our survey responses showed that although there 
are a number of limitations in current-health care settings, they have positive attitude towards limiting infection control.

Majority of the participants had received the training about the importance of hand hygiene in their respective institutions and the importance of hand hygiene is emphasized by their clinical supervisors. Overall, most of them responded that prevention of HAIs is a valuable part of nurse's role.

The result of the present study showed that nurses have a good practice in prevention of HAIs. An important finding from this study is that $94 \%$ of the participants do not adopt any measure of hand hygiene for prevention of HAI prior to patient contact despite $97 \%$ have the knowledge that hand hygiene should be performed before and after direct patient contact. A study in India reported less than desirable level of practice among the health care personnel. ${ }^{13}$

\section{CONCLUSION}

The nursing students had good knowledge regarding prevention of HAIs and this knowledge reflected in their attitude and practice on hand hygiene for the prevention of HAIs. However this study shows that there is need for further improvement in the need of hand hygiene training programme and the training sessions must be conducted more frequently with continuous performance feedback. As nurses are an important group of players in the health care team it is important to provide the best appropriate knowledge and proper training regarding the preventive measures of HAIs from the very early period of their training. Further there is need for an infection prevention team to get more involved with training and updating of existing practices.

Easy, immediate access to hand-hygiene agents and sinks are the key element in improving adherence to hand hygiene. This factor should be taken into consideration in the construction-design of health care infrastructure and settings in order to improve adherence to hand hygiene.

Our results can provide important baseline information about infection control practices in a resource limited countries and highlight some of the barriers to implementing effective infection control policies in Nepal and potentially other similar settings.

\section{Acknowledgement:}

The authors would like to express their sincere gratitude to the participants of the study, hospital administration team of GMCTH and FCH, Prof. Dr. Tu Maya Ghale (Dy. MS, GMCTH) and Mrs. Laxmi Bhandari (Fewacity Institute of Medical Sciences)

\section{REFERENCES}

1. Grippo JO, Chaiyabutr Y, Kois JC. Effects of Cyclic Fatigue Stress-Biocorrosion on Noncarious Cervical Lesions. J Esthet Restor Dent. 2013;25(4):265-72. DOI: 10.1111 jerd.12024.

2. Bardsley PF. The evolution of tooth wears indices. Clin Oral Investig. 2008;12(1):15-9. DOI: 10.1007/s00784-0070184-2.

3. Lopez-Frias F, Castellanos-Cosano L, Martin-Gonzalez J, Llamas-Carreras J, Segura-Egea J. Clinical measurement of tooth wear: Tooth Wear Indices. J Clin Exp Dent. 2012;4 (1): e48-e53. DOI: $10.4317 /$ jced.50592.

4. Larsen IB, Westergaard J, Stoltze K, Larsen AI, Gyntelberg F, 8. Holmstrup P. A clinical index for evaluating and monitoring dental erosion. Community Dent Oral Epidemiol. 2000;28:211-7. DOI: 10.1034/j.16000528.2000.280307.x.

5. øilo G, Dahl BL, Hatle G, Gad A-L. An index for evaluating wear of teeth. Acta Odontol Scand. 1987;45 (5):361-5. DOI: 10.3109/00016358709096359.

6. Fares J, Shirodaria S, Chiu K, Ahmad N, Sherriff M, Bartlett D. A new index of tooth wear. Caries Res. 2009;43 (2):119-25. DOI: $10.1159 / 000209344$

7. Tejaswi B. Effectiveness of Various Diagnostic Tests in Diagnosing Dentinal Hypersensitivity-A Systematic Review. IOSR-JDMS. 2014;1(13):70-92. DOI: 10.9790/0853-13247092.

8. Dorner TE, Muckenhuber J, Stronegger WJ, Ràsky É, Gustorff B, Freidl W. The impact of socio $\square$ economic status on pain and the perception of disability due to pain. Eur J Pain. 2011;15(1):103-9. DOI: 10.1016/ j.ejpain.2010.05.013.

9. Stanford JW, Paffenbarger GC, Kumpula JW, Sweeney WT. Determination of some compressive properties of human enamel and dentin. J Am Dent Assoc. 1958;57 (4):487-95. DOI: 10.14219/jada.archive.1958.0194.

10. Poole DFG, Newman HN, Dibdin GH. Structure and porosity of human cervical enamel studied by polarizing microscopy and transmission electron microscopy. Arch Oral Biol. 1981;26(12):977-82. DOI: 10.1016/00039969(81)90106-0.

11. Heymann HO, Swift Jr EJ, Ritter AV. Sturdevant's art \& science of operative dentistry. Elsevier Health Sciences; 2014 Mar 12.

12. Barbour ME, Parker DM, Allen GC, Jandt KD. Human enamel dissolution in citric acid as a function of $\mathrm{pH}$ in the range $2.30<=\mathrm{pH}<=6.30$ - a nanoindentation study. Eur J Oral Sci. 2003;111(3):258-62. DOI: 10.1034/j.16000722.2003.00039.x.

13. Lupi-Pegurier L, Muller M, Leforestier E, Bertrand M., Bolla M. In vitro action of Bordeaux red wine on the microhardness of human dental enamel. Arch Oral Biol. 2003;48(2):141-5. DOI: 10.1016/s0003-9969(02)002066.

14. Cuy JL, Mann AB, Livi KJ, Teaford MF, Weihs TP. Nanoindentation mapping of the mechanical properties of human molar tooth enamel. Arch Oral Biol. 2002;47(4):281 -91. DOI: 10.1016/s0003-9969(02)00006-7.

15. McCarthy PJ, McClanahan S, Hodges J, Bowles WR. Frequency of localization of the painful tooth by patients presenting for an endodontic emergency. J Endod. 2010;36 (5):801-5. DOI: 10.1016/j.joen.2009.12.035. 